\title{
黑龙江穆棱天然东北红豆杉种群资源特征研究
}

\author{
周志强1 刘 䑣 袁继连 $^{2}$ \\ （1 东北林业大学林学院，哈尔滨 $150040 ） （ 2$ 黑龙江省穆棱林业局 穆棱 157513 )
}

\begin{abstract}
摘 要 根据 74 条样带、 $436.872 \mathrm{hm}^{2}$ 抽样面积的调查结果 对黑龙江穆棱东北红豆杉( Taxus cuspidata) 自然保护区 内天然东北红豆杉种群数量、种群分布与生态因子的相互关系进行了研究 结果表明: 在保护区 $34544 \mathrm{hm}^{2}$ 范围内 天然东北红豆杉种群数量庞大, 个体数高达 179613 株。天然东北红豆杉种群的分布对海拔、坡向、坡位和坡度等 生态因子具有选择性。700 800 m 是种群的最适海拔范围; 分布在阴坡的天然种群数量明显高于阳坡; 山地的中 部和上部更适合东北红豆杉生长; 东北红互杉种群多数分布在坡度 15 度以下的山地, 随着坡度的增加, 天然种群 的数量明显减少。
\end{abstract}

关键词 东北红豆杉 穆陵东北红豆杉自然保护区 种群结构 生态因子

\section{POPULATION CHARACTERISTICS OF YEW (TAXUS CUSPIDATA) IN THE MULING YEW NATURE RESERVE , HEILONGJIANG PROVINCE}

\author{
ZHOU Zhi-Qiang ${ }^{1} \quad$ LIU Tong $^{1}$ and YUAN Ji-Lian ${ }^{2}$ \\ (1 Forestry College , Northeast Forestry University, Harbin 150040 , China) \\ (2 Muling Forestry Bureau of Heilongjiang Province , Muling 157513, China)
}

\begin{abstract}
Based on a field investigation that consisted of 74 sample zones across a total sample area of $436.872 \mathrm{hm}^{2}$, we describe the population characteristics of yew (Taxus cuspidata) , and the relationship between its distribution and site factors. There were a total of 179631 individual yew plants in the $34544 \mathrm{hm}^{2}$ nature reserve, a very large population. The population distribution was correlated to elevation, slope position , aspect and slope gradient. Altitudes between 700 and $800 \mathrm{~m}$ had the greatest number of plants and thus the preferred habitat for natural yew populations. More individuals were found on shady slopes than sunny slopes , and more individuals at the upper and mid-slope positions than at the toe of the slope. There were more yew individuals located on slopes with a slope gradient $<15^{\circ}$ and numbers decreased substantially with increasing slope gradient.
\end{abstract}

Key words Taxus cuspidata, Muling Yew Nature Reserve , Population structure , Site factors

东北红豆杉( Taxus cuspidata) 又称紫杉、赤柏 松, 是红豆杉科红豆杉属( Taxus) 植物, 是我国东北 分布的珍贵第三纪子遗树种、国家 I 级重点保护的 野生濒危植物种类。红豆杉属植物在我国境内分布 共有 3 种 2 个变种(傅立国等,2000) ,即 :东北红豆 杉、喜马拉雅密叶红豆杉( Taxus fauna)、喜马拉雅红 豆杉 $(T$. wallichiana $)$ 及其该种下的两个变种南方红 豆杉 ( $T$. wallichiana var. mairei)、红豆杉 ( $T$. walichiana var. chinensis)。喜马拉雅红豆杉主要分 布在西藏南部(吉隆)2 $500 \sim 3000 \mathrm{~m}$ 地带、缅甸、不 丹、尼泊尔、印度、巴基斯坦和阿富汗; 喜马拉雅密叶 红豆杉及其变种主要分布在我国的华东、中南、西 南、陕西、山西、甘肃、西藏东南、台湾、阿富汗、巴基 斯坦、印度、尼泊尔、不丹、缅甸、马来西亚、印尼和菲
律宾(傅立国等 2000) ;东北红豆杉的自然地理分布 区大致可分为欧亚陆块主体和邻近各岛屿两个部 分, 其大致的地理范围为: $123^{\circ} \sim 155^{\circ} \mathrm{E}, 32^{\circ} 30^{\prime} \sim 53^{\circ}$ $\mathrm{N}$ 垂直分布于海拔 250 1200 m 之间 (图 1) , 欧亚 陆块主体分布区主要包括中国辽宁的本溪、恒仁、宽 甸, 吉林的长白、抚松、靖宇、临江、敦化、和龙、汪清、 安图、珲春, 黑龙江的穆棱、绥阳、绥棱, 朝鲜北部, 俄 罗斯阿穆尔边疆, 邻近岛屿分布区包括: 娥罗斯萨哈 林岛、日本本州、九州岛、北海道、四国岛和朝鲜济州 岛等, 大陆主体分布区和岛屿分布区之间为鞑靼海 峡、日本海、朝鲜海峡和济州海峡, 两部分最近点相 距 $100 \mathrm{~km}$ 以上; 各岛屿间亦远近不一, 接近点不多。 东北红豆杉由于花粉无气囊而传播距离短, 基本上 断绝了与其它近缘种的基因交流，造成明显的地理 
隔离趋势(吴榜华等 ,1995)。

红豆杉属植物体内含治疗癌症和恶性肿瘤的紫 杉醇, 具有很高的药用价值, 是近年来世界范围内研 究与开发的热点。东北红豆杉相对于红豆杉属其它 种, 紫杉醇含量偏低, 东北红豆杉树皮、小枝及针叶 均含有紫杉醇，但以树皮中的紫杉醇含量相对较高， 约 $0.0171 \%$ (王书凯等 ,1997)。以往对红豆杉属植 物的研究多集中在不同种类紫杉醇的含量与提取 (阎家麒等 ,1994; Russin \& Elliss , 1995 ; Yuan et al. , 2002 ; Shi et al .,2003)、紫杉醇应用(王冰等，1998； 梅兴国等 ,2002; Gustafson et al. , 2003 ; Jennewein et $a l$. , 2003)、栽培技术(吴榜华等,1996 ; 崔成万等， 2003 ; 高兆蔚等,2003 ;翁志远等,2003)等方面，对红 豆杉属植物种群和群落水平的研究相对较少, 且仅 局限于少数种，如 :南方红豆山和欧洲红豆杉( Taxus baccta ) (廖文波等,1997;2002a ;2002b ; 刘仁林等， 1997 李先琨等,1999; 罗文训,2000；茹文明，2001； Dempsey \& Hook, 2000 ; Thomas \& Polwart, 2003 ; Hulme，1996）,对东北红豆杉种群和群落自然属性 的研究仅局限于东北红豆杉地理分布 ( 吴榜华等, 1995 ; 柏广新等 ,2002)、开花与结实规律(马小军等, 1996 ;程广有等,2001), 对天然东北红豆杉资源特 征、种群和群落生态等方面研究尚属空白。

东北红豆杉作为地带性植被一温带阔叶红松林 的亚乔木树种和伴生种类, 其生态生物学特性具有 散生、喜庇荫和冷湿的生境、生长缓慢等特点 (周以 良, 1986 柏广新等,2002)，因此，天然东北红豆杉资 源十分有限。黑龙江穆棱东北红豆杉自然保护区位 于长白山脉北端, 老爷岭南坡, 该区域在植被区划上 属于 温带针阔混交林区域” (中国植被编委会, 1980) 其地带性植被是以红松 (Pinus koraiensis) 为主 的针阔混交林 (周以良, 1992)。良好的自然条件使 该地区成为东北红豆杉在黑龙江省的集中分布区， 加之地方林业管理部门对东北红豆杉的保护措施得 力, 保护区内相对丰富天然东北红豆杉资源保存完 好 根据 2003 年春季组织的对保护区天然东北红豆 杉资源的调查, 在 $34544 \mathrm{hm}^{2}$ 的范围内, 东北红豆杉 天然种群庞大, 个体数目接近 18 万株, 最大个体胸 径达 $92 \mathrm{~cm}$ 树高 20 余米, 种群的年龄结构复杂, 群 落类型多样。本文根据野外 74 条样带的调查结果, 研究了黑龙江穆棱东北红豆杉自然保护区的天然东 北红豆杉种群数量、种群分布与立地因子的相互关 系, 以填补本区域此方面研究的空白。

\section{1 研究地点概况}

研究地点位于黑龙江省南部穆棱东北红豆杉自 然保护区, 保护区东西宽 $33 \mathrm{~km}$, 南北长 $31 \mathrm{~km}$, 总面 积 $34544 \mathrm{hm}^{2}$ 地理坐标为 :东经 $130^{\circ} 00^{\prime} \sim 130^{\circ} 28^{\prime}$, 北纬 $43^{\circ} 49^{\prime} \sim 44^{\circ} 06^{\prime}$ (图 1)。该区为浑圆低缓绵延的 群山所环抱, 海拔在 500 900 m 之间 相对高度 150 $\sim 450 \mathrm{~m}$, 气候属温带大陆性季风气候, 无霜期 $110 \mathrm{~d}$ 左右(据 $1980 \sim 1988$ 年气象资料统计), 年降雨量 $440 \sim 510 \mathrm{~mm}$, 年平均温度在 $-2{ }^{\circ} \mathrm{C}$ 左右, $\geqslant 10{ }^{\circ} \mathrm{C}$ 年 积温为 $1736.7{ }^{\circ} \mathrm{C}$ 。暗棕色森林土是保护区的地带 性土壤。植被是以红松、红皮云杉( Picea koraiensis) 、臭冷杉 (Abies nephrolepis)、紫椴 (Tilia amurensis)、水曲柳 (Fraxinus mandshurica)、白桦 (Betula platyphylla)、枫桦 (B. costata)、山杨 (Populus dahuri$c a$ ) 和蒙古柇 (Quercus mongolica) 等为主的温带针阔 混交林。

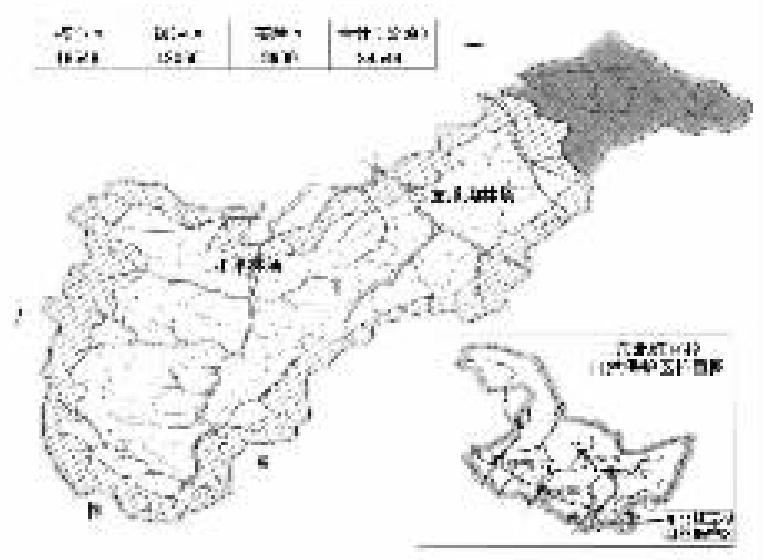

图 1 研究地点位置与研究区域示意图 Fig. 1 Location and scale of study area

保护区范围内有植物 163 科 472 属 1135 种, 其 中地衣、苔藓植物 47 科 84 属 184 种; 薕类植物 19 科 34 属 66 种; 裸子植物 3 科 6 属 11 种; 被子植物 94 科 348 属 874 种。有国家 I 级重点保护野生濒危植 物 1 种，即红豆杉科红豆杉属的东北红豆杉; 国家 II 级重点保护野生植物 7 种, 即杨柳科钻天柳属钻天 柳( Chosenia arbutifolia)、松科松属的红松、椴树科椴 树属紫椴、芸香科黄檗属的黄檗 (Phellodendron $a$ murense) 、木犀科白蜡树属水曲柳、黑三棱科黑三棱 属北方黑三棱 ( Sparganium hyperboreum)、泽泻科慈菇 属浮叶慈菇 ( Sagittaria natans)。此外, 还有受黑龙 江省重点保护的植物, 如 翠雀( Delphinium grandiflorum)、松下兰 (Monotropa hypopitys)、笃斯越桔 ( Vac- 
cinium uliginosum)、林奈草 ( Linnaea borealis)、山丹 ( Lilium pumilum)、授草 (Spiranthes sinensis)、大花杓兰 (Cypripedium macranthum) 等。

\section{2 研究方法}

\section{1 样带的抽样与设置}

根据黑龙江穆棱东北红豆杉自然保护区 34544 $\mathrm{hm}^{2}$ 所辖 156 个林班的立地因子数据和东北红豆杉 的生态生物学特性 将林班划分阴坡与阳坡两类, 按 照阴坡 $49 \%$ 、阳坡 $45 \%$ 的抽样强度, 共随机抽取 74 个林班进行样带调查,74 条样带的总面积达到 $436.872 \mathrm{hm}^{2}$ 。其中阴坡 47 条样带, 阳坡 27 条样带。 抽样林班在各个林场的分布见表 1 。

在确定抽样林班后，依据抽样样带必须贯穿整 个林班的原则, 首先在林相图上确定样带的位置, 包 括起始点和终点的坐标、方位角, 然后利用手持 GPS (GARMIN-etrex) 在野外找到样带的起始点, 根据预 先设定的样带进行天然东北红豆杉资源的调查。

\section{2 数据的收集与整理}

根据植株高度, 将天然东北红豆杉个体分为更 新层 (植株高度小于 $1 \mathrm{~m}$ ), 演替层 (植株高度 $1 \sim 5$ $\mathrm{m}$ ) 和乔木层 (植株高度大于 $5 \mathrm{~m}$ )。以预设的样带为 中心线, 在样带左右各 $5 \mathrm{~m}$ 的范围内记录出现的东 北红豆杉更新层和演替层个体的地(胸)径、高度、生 长状况、地理坐标及相关立地因子数据, 如 坡度、坡 位、坡向、海拔等指标; 在样带左右各 $10 \mathrm{~m}$ 的范围记 录出现的东北红豆杉乔木个体的胸径、高度、生长状 况、地理坐标及相关的立地因子数据。将野外调查 数据汇总 建立数据库, 统计不同坡向、不同群落层 次的单位面积东北红豆杉种群数量, 计算保护区内 天然东北红豆杉种群总量, 并根据样带调查的结果, 运用统计软件, 分析比较不同生境下天然种群的数
量, 不同生态因子与天然东北红豆杉种群分布的关 系。

\section{3 结果分析}

3.1 黑龙江穆棱东北红豆杉自然保护区天然东北 红豆杉的种群数量

根据野外样带调查的数据资料, 保护区内天然 分布的东北红豆杉种群数量庞大, 在 $34544 \mathrm{hm}^{2}$ 范 围内 共分布有天然东北红豆杉 179613 株, 阴坡分 布有 127416 株，阳坡分布有 52197 株，实测单株最 大胸径达 $92 \mathrm{~cm}$ ，树高 $13 \mathrm{~m}$ 。在总计 74 条样带中， 有天然东北红豆杉分布的样带共 49 条, 其中 41 条 分布在阴坡, 8 条样带分布在阳坡, 没有东北红豆杉 分布的样带共 25 条, 其中 11 条分布在阳坡, 14 条分 布在阴坡。根据对不同坡向 (阴坡、阳坡) 和不同层 次 (乔木层、演替层和更新层) 的天然东北红豆杉数 量统计(表 2) 发现: 阴坡和阳坡单位面积上处于更 新层的天然东北红豆杉幼苗数量差异不大, 每公顷 均达到 4 株以上; 不论在阴坡或阳坡，处于演替层的 天然东北红豆杉个体数量很少; 处于乔木层的东北 红豆杉个体数量, 阴坡 $\left(0.7518\right.$ 株 $\left.\mathrm{hm}^{-2}\right)$ 相对于阳 坡 $\left(0.4924\right.$ 株 $\left.\mathrm{hm}^{-2}\right)$ 为多。在自然保护区范围内， 天然东北红豆杉个体的胸 (地) 径的分布有如下规律 (图 2): 胸(地)径在 $4 \mathrm{~cm}$ 以下的个体多, 占东北红豆 杉资源总量的 $76.82 \%$ 。胸径超过 $16 \mathrm{~cm}$ 的东北红 互杉个体占种群总量的 $20.87 \%$ 。胸径在 4 16 cm 区间个体数量较少, 仅占资源总量的 $2.32 \%$ 。根据 对不同坡向、不同径阶范围东北红豆杉样株平均树 高的统计分析(图 3), 当胸径超过 $24 \mathrm{~cm}$ 后, 东北红 豆杉的树高变化幅度较小,个体的高生长基本趋于 平稳 胸(地)径在 $0 \sim 24 \mathrm{~cm}$ 区间东北红豆杉个体的 高生长最为迅速。

表 1 保护区内各林场的林班分布与抽样情况

Table 1 Scalar of compartments and samples in yew natural reserve

\begin{tabular}{|c|c|c|c|c|c|c|}
\hline \multirow{2}{*}{$\begin{array}{c}\text { 林场 } \\
\text { Location name }\end{array}$} & \multicolumn{2}{|c|}{$\begin{array}{l}\text { 保护区内林班数 } \\
\text { Compartment No. }\end{array}$} & \multicolumn{2}{|c|}{$\begin{array}{c}\text { 抽样数 } \\
\text { Sample No. }\end{array}$} & \multicolumn{2}{|c|}{$\begin{array}{c}\text { 抽样强度 } \\
\text { Sampled percentage }(\%)\end{array}$} \\
\hline & $\begin{array}{c}\text { 阴坡 } \\
\text { Shady aspect }\end{array}$ & $\begin{array}{c}\text { 阳坡 } \\
\text { Sunny aspect }\end{array}$ & $\begin{array}{c}\text { 阴坡 } \\
\text { Shady aspect }\end{array}$ & $\begin{array}{c}\text { 阳坡 } \\
\text { Sunny aspect }\end{array}$ & $\begin{array}{c}\text { 阴坡 } \\
\text { Shady aspect }\end{array}$ & $\begin{array}{c}\text { 阳坡 } \\
\text { Sunny aspect }\end{array}$ \\
\hline 和平林场 Heping & 53 & 39 & 25 & 15 & 47 & 38 \\
\hline 龙爪沟林场 Longzhaogou & 20 & 10 & 8 & 3 & 40 & 30 \\
\hline 共和林场 Gonghe & 21 & 10 & 12 & 8 & 57 & 80 \\
\hline 杨木桥林场 Yangmuqiao & 2 & 1 & 2 & 1 & 100 & 100 \\
\hline 合计 Summary & 96 & 60 & 47 & 27 & 49 & 45 \\
\hline
\end{tabular}


表 2 保护区内天然东北红豆杉种群数量统计

Table 2 Statistic of natural yew population in natural reserve

\begin{tabular}{|c|c|c|c|c|c|c|c|}
\hline & \multirow[b]{2}{*}{$\begin{array}{l}\text { 项目 } \\
\text { Item }\end{array}$} & \multirow{2}{*}{$\begin{array}{c}\text { 样带内东北 } \\
\text { 红豆杉数量 } \\
\text { No. of yew } \\
\text { in sample }\end{array}$} & \multicolumn{2}{|c|}{ 样带 Sample } & \multirow[b]{2}{*}{$\begin{array}{l}\text { 单位面积 } \\
\text { 株数 } \\
\text { No. per } \mathrm{hm}^{2}\end{array}$} & \multirow[b]{2}{*}{$\begin{array}{c}\text { 保护区内不同 } \\
\text { 坡向面积 } \\
\text { Aspect area }\end{array}$} & \multirow{2}{*}{$\begin{array}{c}\text { 东北红豆杉 } \\
\text { 资源总量 } \\
\text { Summary } \\
\text { No. of yew }\end{array}$} \\
\hline & & & $\begin{array}{c}\text { 样带总长度 } \\
\text { Sample length } \\
(\mathrm{m})\end{array}$ & $\begin{array}{c}\text { 样带面积 } \\
\text { Sample area } \\
\left(\mathrm{hm}^{2}\right)\end{array}$ & & & \\
\hline \multirow{4}{*}{$\begin{array}{l}\text { 阳坡 } \\
\text { Sunny slope }\end{array}$} & 更新层 Seedling & 118 & 27418 & 27.418 & 4.3037 & 10883 & 46838 \\
\hline & 演替层 Younger & 0 & 27418 & 27.418 & 0 & 10883 & 0 \\
\hline & 乔木层 Tree & 27 & 27418 & 54.836 & 0.4924 & 10883 & 5359 \\
\hline & 合计 Summary & 145 & - & 109.672 & 4.7597 & 10883 & 52197 \\
\hline \multirow{5}{*}{$\begin{array}{l}\text { 阴坡 } \\
\text { Shady slope }\end{array}$} & 更新层 Seedling & 372 & 81800 & 81.8 & 4.5477 & 23661 & 107602 \\
\hline & 演替层 Younger & 7 & 81800 & 81.8 & 0.0856 & 23661 & 2025 \\
\hline & 乔木层 Tree & 123 & 81800 & 163.6 & 0.7518 & 23661 & 17789 \\
\hline & 合计 Summary & 502 & - & 327.2 & 3.7164 & 23661 & 127416 \\
\hline & a计 Total & 647 & 109218 & 436.872 & 8.4761 & 34544 & 179613 \\
\hline
\end{tabular}

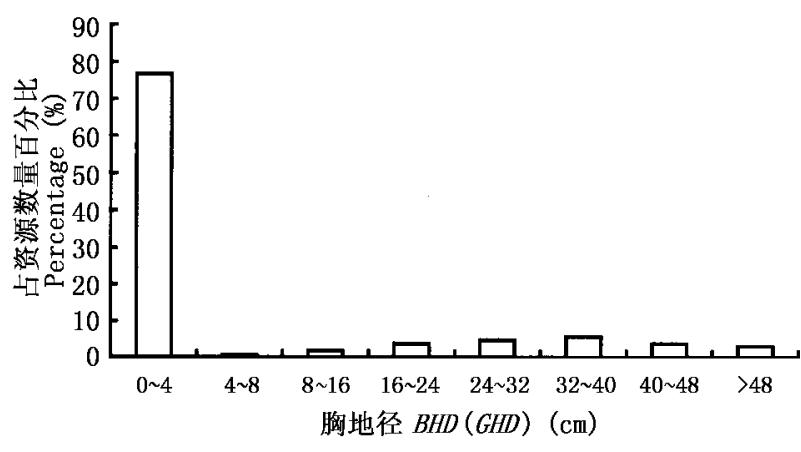

图 2 保护区内天然东北红豆杉种群径经分布

Fig.2 $B H D(G H D)$ distribution of yew population in natural reserve

3.2 天然东北红豆杉种群分布与生态因子的相互 关系

\subsection{1 东北红豆杉种群分布与海拔的关系}

根据野外样带的调查数据, 我们对 647 株调查 的东北红豆杉个体进行了统计 (表 3)。结果显示, 东北红豆杉个体在不同的海拔高度、坡向、森林群落 层次上呈现不同的分布特点: 1) 天然种群的数量在 不同的海拔高度上分布不均:在保护区范围内 东北 红豆杉个体在海拔 $700 \sim 800 \mathrm{~m}$ 区间分布数量最多， 该区间分布的东北红豆杉植株占实测总量的 $68.47 \%$; 在海拔低于 $700 \mathrm{~m}$ 的山地，东北红豆杉个 体的数量占调查总量的 $21.95 \%$;当海拔超过 800 $\mathrm{m}$,天然分布的东北红豆杉数量明显减少, 仅占总量 的 $9.58 \%$ 。2) 不同海拔高度上, 东北红豆杉分布在 阴坡的数量要远大于阳坡:在海拔 $800 \mathrm{~m}$ 以上的山 地 东北红豆杉阴坡数量与阳坡数量之比为 $41: 21$; 当海拔在 700 至 $800 \mathrm{~m}$ 之间,阴坡阳坡数量比值为 $352: 91$; 而海拔低于 $700 \mathrm{~m}$, 该比值为 $117: 31$ 。3) 不 同的海拔高度上, 东北红豆杉种群在不同森林群落 层次上的数量分布存在差异 :对于更新层来说, 700

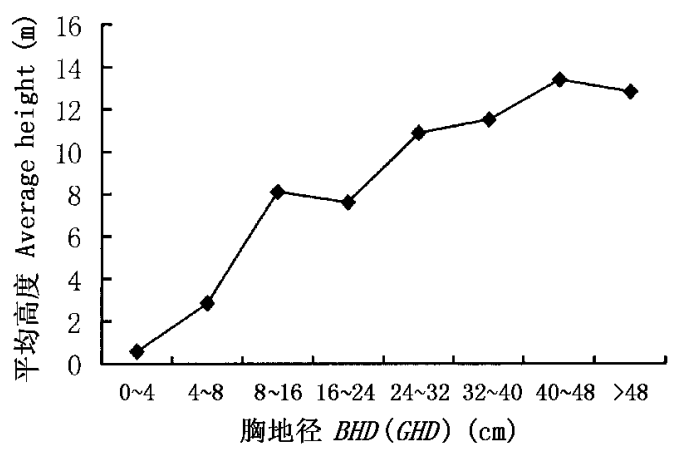

图 3 不同径阶的平均树高

Fig.3 The average tree height of different $B H D(G H D)$ group $\sim 800 \mathrm{~m}$ 的山地上, 处于更新层的东北红豆杉数量 最多,阴坡达 281 株, 阳坡为 72 株; 当海拔低于 700 $\mathrm{m}$,阴坡更新层的红豆杉个体数量 81 株, 阳坡为 27 株 海拔超过 $800 \mathrm{~m}$, 更新层东北红豆杉的数量急剧 减少,阴坡仅为 19 株, 阳坡 18 株。对于个体高度在 1 $5 \mathrm{~m}$ 之间的演替层, 不同海拔高度上东北红豆杉 个体数量均很低, 没有明显差异。在乔木层, 东北红 豆杉个体数量随海拔高度和坡向的变化很大,700 $800 \mathrm{~m}$ 的山地上的个体最多, 阴坡与阳坡的数量比 为 $68: 19$; 在海拔低于 $700 \mathrm{~m}$ 时, 该值为 $27: 4$;海拔超 过 $800 \mathrm{~m}$, 该值仅为 $21: 3$ 。

总体上,700 $800 \mathrm{~m}$ 是东北红豆杉种群在保护 区范围内分布的最适海拔范围, 海拔超过或低于这 一范围, 天然东北红豆杉种群的分布数量明显减少; 在不同的海拔高度上,阴坡较之阳坡更适合东北红 豆杉生长与种群扩展。

\subsection{2 穆棱东北红豆杉种群的分布与坡位的关系}

调查中将山地分为上、中、下 3 个坡位等级记录 东北红豆杉个体的分布 然后分别不同坡位、坡向和 森林群落层次, 对野外调查的647株东北红豆杉进 
表 3 不同海拔高度天然东北红豆杉种群统计

Table 3 Statistic of sampled yew at different elevation

\begin{tabular}{|c|c|c|c|c|c|}
\hline \multirow[b]{2}{*}{$\begin{array}{c}\text { 海拔 } \\
\text { Elevation }\end{array}$} & \multicolumn{5}{|c|}{ 项目 Item } \\
\hline & $\begin{array}{l}\text { 坡向 } \\
\text { Slope }\end{array}$ & $\begin{array}{l}\text { 层次 } \\
\text { Layer }\end{array}$ & $\begin{array}{l}\text { 株数 } \\
\text { No. }\end{array}$ & $\begin{array}{c}\text { 平均胸 (地)径 } \\
\text { Average } B H D(G H D) \\
(\mathrm{cm})\end{array}$ & $\begin{array}{c}\text { 平均树高 } \\
\text { Average height } \\
(\mathrm{m}) \\
\end{array}$ \\
\hline \multirow{6}{*}{$\geqslant 800 \mathrm{~m}$} & \multirow{3}{*}{ 阴坡 Shady slope } & 更新层 Seedling & 19 & 0.6 & 0.27 \\
\hline & & 演替层 Younger & 1 & 10 & 4 \\
\hline & & 乔木层 Tree & 21 & 40.85 & 11 \\
\hline & \multirow{3}{*}{ 阳坡 Sunny slope } & 更新层 Seedling & 18 & 1.43 & 0.54 \\
\hline & & 演替层 Younger & 0 & 0 & 0 \\
\hline & & 乔木层 Tree & 3 & 28.7 & 11.5 \\
\hline \multirow{6}{*}{$700 \sim 800 \mathrm{~m}$} & \multirow{3}{*}{ 阴坡 Shady slope } & 更新层 Seedling & 281 & 0.78 & 0.62 \\
\hline & & 演替层 Younger & 3 & 14 & 3.2 \\
\hline & & 乔木层 Tree & 68 & 36.46 & 11.6 \\
\hline & \multirow{3}{*}{ 阳坡 Sunny slope } & 更新层 Seedling & 72 & 0.95 & 0.66 \\
\hline & & 演替层 Younger & 0 & 0 & 0 \\
\hline & & 乔木层 Tree & 19 & 32.32 & 11.68 \\
\hline \multirow{6}{*}{$<700 \mathrm{~m}$} & \multirow{3}{*}{ 阴坡 Shady slope } & 更新层 Seedling & 81 & 0.83 & 0.54 \\
\hline & & 演替层 Younger & 3 & 4.67 & 2.33 \\
\hline & & 乔木层 Tree & 27 & 29.5 & 10.04 \\
\hline & \multirow{3}{*}{ 阳坡 Sunny slope } & 更新层 Seedling & 27 & 1.41 & 0.83 \\
\hline & & 演替层 Younger & 0 & 0 & 0 \\
\hline & & 乔木层 Tree & 4 & 37.5 & 9.5 \\
\hline
\end{tabular}

表 4 不同坡位天然东北红豆杉种群统计

Table 4 Statistic of sampled yew on different slope position

\begin{tabular}{|c|c|c|c|c|c|c|c|}
\hline \multirow{3}{*}{$\begin{array}{c}\text { 坡位 } \\
\text { Slope position }\end{array}$} & \multirow{3}{*}{$\begin{array}{l}\text { 群落层次 } \\
\text { Layer }\end{array}$} & \multicolumn{6}{|c|}{$\begin{array}{c}\text { 不同坡向株数、胸(地)径和高度 } \\
\text { Yew No. , BHD }(G H D) \text { and height on different slope }\end{array}$} \\
\hline & & \multicolumn{3}{|c|}{ 阳坡 Sunny slope } & \multicolumn{3}{|c|}{ 阴坡 Shady slope } \\
\hline & & $\begin{array}{l}\text { 株数 } \\
\text { Yew No. }\end{array}$ & $\begin{array}{c}\text { 胸(地)径 } B H D \\
(G H D)(\mathrm{cm})\end{array}$ & $\begin{array}{c}\text { 树高 } \\
\text { Height }(\mathrm{m})\end{array}$ & $\begin{array}{c}\text { 株数 } \\
\text { Yew No. }\end{array}$ & $\begin{array}{c}\text { 胸(地)径 } B H D \\
(G H D)(\mathrm{cm})\end{array}$ & $\begin{array}{c}\text { 树高 } \\
\text { Height }(\mathrm{m})\end{array}$ \\
\hline \multirow{3}{*}{ 坡上 Upper slope } & 更新层 Seedling & 60 & 0.83 & 0.44 & 101 & 0.60 & 0.92 \\
\hline & 演替层 Younger & 0 & 0 & 0 & 3 & 4.67 & 2.33 \\
\hline & 乔木层 Tree & 6 & 18.33 & 10 & 26 & 33.30 & 11.59 \\
\hline \multirow{3}{*}{ 坡中 Middle slope } & 更新层 Seedling & 39 & 1.72 & 1.05 & 269 & 0.73 & 0.59 \\
\hline & 演替层 Younger & 0 & 0 & 0 & 4 & 12 & 3.37 \\
\hline & 乔木层 Tree & 16 & 39 & 12.53 & 88 & 36.05 & 11.53 \\
\hline \multirow{3}{*}{ 坡下 Toe slope } & 更新层 Seedling & 19 & 0.88 & 0.71 & 9 & 0.9 & 0.65 \\
\hline & 演替层 Younger & 0 & 0 & 0 & 0 & 0 & 0 \\
\hline & 乔木层 Tree & 4 & 29 & 10.25 & 3 & 31.33 & 8 \\
\hline
\end{tabular}

行了统计 (表 4)。发现天然东北红豆杉种群的分 布，对于坡位这一生态因子具有很强的选择性，总体 来讲，不论阴坡或者阳坡，在坡的中部和上部东北红 豆杉分布较多坡的下部分布数量很少, 在阳坡, 坡 中部、上部的东北红豆杉数量占阳坡个体总量的 $84 \%$;在阴坡的中部、上部，该值更达到 $97.61 \%$ 。由 于保护区的所辖范围地处穆棱林业局边缘, 以往对 天然东北红豆杉的破坏轻微, 天然种群基本处于原 生状态，因此可以认为，东北红豆杉对于坡位的选择 性是种群的自然属性。对于不同坡位、不同群落层 次东北红豆杉个体的生长状况 (平均胸径、平均树
高)的比较, 由于统计样本的数量差异较大, 无明显 的规律，有待于后续工作进行更深入的研究。

\section{2 .3 东北红豆杉种群分布与坡度的关系}

调查样带的统计结果显示 (表 5) ,坡度的陡缓 对天然东北红豆杉种群分布也存在一定程度影响。

在阴坡,随着坡度的增加，东北红豆杉种群数量 基本呈下降的趋势: 在坡度小于 10 度的山地范围 内, 调查的东北红豆杉数量达 236 株 坡度在 $10 \sim 15$ 度之间 种群数量为 200 株; 而当坡度超过 15 度, 种 群数量仅为 67 株。在阳坡, 种群数量没有明显的随 坡度变化规律。 
表 5 不同坡度天然东北红豆杉种群统计

Table 5 Statistic of sampled yew on different gradient

\begin{tabular}{|c|c|c|c|c|c|c|c|}
\hline \multirow{3}{*}{$\begin{array}{c}\text { 坡度 (度) } \\
\text { Gradient }\end{array}$} & \multirow{3}{*}{$\begin{array}{c}\text { 群落层次 } \\
\text { Layer }\end{array}$} & \multicolumn{6}{|c|}{$\begin{array}{c}\text { 不同坡向株数、胸(地)径和高度 } \\
\text { Yew No. ,BHD }(G H D) \text { and height on different aspect }\end{array}$} \\
\hline & & \multicolumn{3}{|c|}{ 阳坡 Sunny aspect } & \multicolumn{3}{|c|}{ 阴坡 Shady aspect } \\
\hline & & $\begin{array}{c}\text { 株数 } \\
\text { Yew No. }\end{array}$ & $\begin{array}{c}\text { 胸(地)径 } B H D \\
(G H D)(\mathrm{cm})\end{array}$ & $\begin{array}{c}\text { 树高 } \\
\text { Height }(\mathrm{m})\end{array}$ & $\begin{array}{c}\text { 株数 } \\
\text { Yew No. }\end{array}$ & $\begin{array}{c}\text { 胸(地)径 } B H D \\
(G H D)(\mathrm{cm})\end{array}$ & $\begin{array}{c}\text { 树高 } \\
\text { Height }(\mathrm{m})\end{array}$ \\
\hline \multirow{3}{*}{$>15$} & 更新层 Seedling & 53 & 0.83 & 0.42 & 45 & 0.64 & 0.72 \\
\hline & 演替层 Younger & 0 & 0 & 0 & 2 & 10 & 2.8 \\
\hline & 乔木层 Tree & 7 & 20.29 & 10.36 & 20 & 30.7 & 10.73 \\
\hline \multirow{3}{*}{$10 \sim 15$} & 更新层 Seedling & 14 & 1.06 & 0.86 & 149 & 0.86 & 0.64 \\
\hline & 演替层 Younger & 0 & 0 & 0 & 4 & 9 & 2.75 \\
\hline & 乔木层 Tree & 7 & 33.86 & 12.71 & 47 & 39.96 & 11.64 \\
\hline \multirow{3}{*}{$<10$} & 更新层 Seedling & 50 & 1.47 & 0.91 & 185 & 0.68 & 0.47 \\
\hline & 演替层 Younger & 0 & 0 & 0 & 1 & 10 & 4 \\
\hline & 乔木层 Tree & 13 & 37.15 & 11.46 & 50 & 33.12 & 11.28 \\
\hline
\end{tabular}

\section{4 讨 论}

天然东北红豆杉虽然在自然保护区有较大的种 群数量和相对集中的分布, 但种群的结构不合理, 处 于更新层的东北红豆杉幼苗居多, 大径级的东北红 豆杉个体也较多, 但处于演替层的东北红豆杉数量 很少, 这样的种群结构不利于东北红豆杉种群的发 展 其原因归结起来可能来自如下两个方面：

1) 原生生境改变对种群发展的不利影响

东北红豆杉作为地带性温带针阔混交林的伴生 树种, 主要出现在保护区以红松为主针阔叶混交林 的亚林层中 (周以良等, 1985; 周以良,1986)。在适 合其生长发育的林分中，上层的红松、云杉、冷杉等 针叶树和紫椴、枫桦、水曲柳等阔叶树为东北红豆杉 生长提供相对了湿润、庇荫的生境条件。据研究, 东 北红豆杉在湿度 $70 \%$ 以上的生境条件下生长良好 (柏广新等, 2002)。在过去几十年间, 当地原生森林 植被遭到反复采伐利用, 原生东北红豆杉种群由于 材质和当地林业管理部门的保护意识等原因，被较 好地保存下来, 但由于上层林冠的优势树种基本被 伐除, 使得多数大径级、生理成熟的东北红豆杉个体 失去了原有湿润、庇荫的生境条件, 种群退化、生长 不良。在现实林分中, 有相当部分的大径级东北红 豆杉表现出生长不良的状况，如:树冠干枯、植株部 分或全部枯死、矮化、结实率下降等。这些都严重影 响种群的天然更新和扩展。因此, 加强保护措施, 恢 复适于东北红豆杉生长的生境条件, 是保存和发展 现有种群所面临的迫切任务。

2) 种群的生态生物学特性决定了该种在种间 竞争中处于不利的位置
天然东北红豆杉大多生长在林分郁闭度较大的 森林中，在阴暗的林下缺乏种子传播的有效动力， 如: 凤等 种群的扩散受到影响, 天然更新的个体多 分布在母树周围、种间竞争压力小的空间点。东北 红豆杉一般在 $40 \sim 60$ 年后开始结实, 结实量很低, 且年份之间和个体之间的结实量差异很大, 种子萌 发在庇荫和全光下的差异高达 $60 \%$ (柏广新等, 2002)。东北红豆杉生长极其缓慢, 通过年轮的查 数, 胸径 $33 \mathrm{~cm}$ 的东北红豆杉，树龄超过 450 年。所 有这些生态生物学特性, 直接影响了天然种群的结 构和种群的发展。

黑龙江省穆棱林业局的天然东北红豆杉种群数 量较庞大, 但种群结构不合理及原生生境破坏较严 重 致使种群仍然处于濒危状态, 因此, 在进一步深 入研究种群的发生发展规律的同时, 应着力加强保 护。保护的措施包括:严禁盗采盗伐东北红豆杉; 对 天然种群分布相对集中的区域应建立围栏进行封育 管理 对东北红豆杉母树集中的区域进行适当的林 下植被清理 增加天然下种的机会等。

\section{参 考 文 献}

Bai,G.X. (柏广新) \& B.H. Wu (吴榜华). 2002. Research in China's Taxus cuspidata. Beijing: China Forestry Publishing House. 259. (in Chinese)

Cheng, G.Y.(程广有) \& X. H. Shen (沈熙环). 2001. Flower distribution and bearing fruit regulation of Taxus cuspidata. Journal of Northeast Forestry University (东北林业大学学报), 29: 44 46. (in Chinese with English abstract)

Chinese Vegetation Editorial Board (中国植被编委会). 1980. Chinese vegetation. Beijing: Science Press. 1375. (in Chinese) Chung, J. M. 1999. Allozyme variation in Korean populations of Taxus cuspidata (Taxaceae) . Scandinavian Journal of Forest Research, 14:103 110 .

Cui, C.W. (崔成万), F.Y. An(安丰云), X.F. Liu(刘喜发), 
M.S. Liu(刘美善), L. W. Zhang (张立旺), X. Q. Wang(王 学强), D.J. Jiang (姜德君), Q. Mu(牟强), B. K. Li (李保 坤) \& S. M. Li(李树明). 2003. Study on cultivation technique of Taxus cuspidata. Quarterly Forest By-Product and Speciality in China(中国林副特产), 2: 8 11. (in Chinese)

Dempsey, D. \& I. Hook. 2000. Yew ( Taxus) species-chemical and morphological variations. Pharmaceutical Biology, 38:274 280 .

Fu, L.G. (傅立国), T.Q.Chen (陈潭清), K. Y. Lang(郎楷永) \& T. Hong (洪涛). 2000. Higher plants of China (Vol. 3). Qingdao: Qingdao Publishing House. (in Chinese)

Gao, Z.W. (高兆蔚), T.L.Wang(王挺良), G.S. Zou(邹高顺) \& M. M. Lin(林木木). 2003. Study on distribution, habitat and cultivation techneque of Taxus wallichiana var. mairei in Fujian Province. East China Forest Management (华东森林经 理), 17: 6 13. (in Chinese with English abstract)

Gustafson, D. L. 2003. Analysis of docetaxel pharmacokinetics in humans with the inclusion of later sampling time-points afforded by the use of a sensitive tandem LCMS assay. Cancer Chemotherapy \& Pharmacology, 52:159 166 .

Hulme, P. E. 1996. Natural regeneration of yew (Taxcus baccata L. ). Journal of Ecology, 84:853 861.

Jennewein, S., C. D. Rithner, R. M. Williams \& R. Croteau. 2003. Taxoid metabolism: taxoid 14- $\beta$-hydroxylase is a cytochrome P450-dependent monooxygenase. Rchives of iochemistry \& Biophysics, 413:262 270.

Li, X.K. (李先琨) , Y.Q. Huang (黄玉清) \& Z.M. Su (苏宗 明). 1999. Preliminary studies on interconnections among main tree population of Taxus chinensis var. mairei community. Chinese Journal of Ecology (生态学杂志), 18:10 14. (in Chinese with English abstract)

Liao, W. B. (廖文波),Z.Y. Su(苏志尧),D.F. Cui(崔大方)， Z.M. Chen(陈志明) \& Z. Q. Zhang(张志权).2002a. Study on plant communities of Taxus mairei in North Guangdong, China. Acta Botanica Yunnanica (云南植物研究) , 24:295 306 . (in Chinese with English abstract)

Liao, W. B. (廖文波), Z. Q. Zhang(张志权), Z. M. Chen(陈志 明), C. G. Tang (唐长根) \& S. F. Deng (邓世福).2002b. Community types, phenology and propagation of characteristics of Taxus mairei in North Guangdong. Chinese Journal of Applied Ecology (应用生态学报), 13:795 801. (in Chinese with English abstract)

Liao, W.B. (廖文波), Z.Q. Zhang (张志权) \& Z.Y. Su (苏 志尧). 1997. Importance and exigency on study of protection biology of anticancer plant Taxus mairei. Ecological Science (生 态学杂志), 15:17 20. (in Chinese with English abstract)

Liu, R.L. (刘仁林) \& L.L.Zhu (朱玲林). 1997. Study on spatial pattern of population of Taxus mairei in its natural community. 1997. Environment and Exploration(环境与开发), 12: 3 8. (in Chinese with English abstract)

Luo, W.X. (罗文训) .2000. Structure characteristics of Taxus chinensis var. mairei community. Subtropical Plant Research Communications (亚热带植物通讯), 29(3): 39 42. (in Chinese with English abstract)

Ma, X. J. (马小军), W. L. Ding (丁万隆) \& Z. Chen (陈震) .
1996. Temperature influence on seed sprouting of Taxus cuspidata. Chinese Traditional Medicine Magazine(中国中药杂志), 21:20 22. (in Chinese with English abstract)

Mei, X.G. (梅兴国), Q.J.Wu(吴奇君),Z.R.Jiang(江振然)\& J.L. Chang(常俊丽) . 2002. Regulation of Taxol biosynthesis in cell suspension culture of Taxus cuspidata. Life Science Research (生命科学研究), 6:152 155. (in Chinese with English abstract)

Ru, W. M. (茹文明). 2001. Investigation of Taxus mairei on menghe forest region of yangcheng county in Shanxi Province. Bulletin of Botanical Research (植物研究), 21:42 46. (in Chinese with English abstract)

Russin, W. A. \& D. D. Elliss. 1995. Immunocytochemical localization of Taxol in Taxus cuspidata. International Journal of Plant Science, 156: $668 \sim 679$.

Shi, Q.W., T. L. Petzke, F. Sauriol, O. Mamer \& L. O. Zamir. 2003. Taxanes in rooted cuttings vs. mature Japanese yew. Canadian Journal of Chemistry, 81:64 74.

Thomas, P.A. \& A. Polwart. 2003. Taxus baccata L. Journal of Ecology, 91: $489 \sim 524$.

Wang, S. K. (王书凯) \& F. Chen(陈凡). 1997. Study on Taxol content of Taxus cuspidata. Forest Science and Technology(林业 科技通讯)，7:19 20. (in Chinese)

Wang, B. (王冰) \& H.Y. Zheng(郑红月). 1998. Identifying of yew (Taxus cuspidata) crude drug. Journal of Traditional Chinese Medicine(中草药), 29:267 269. (in Chinese with English abstract)

Weng, Z.Y. (翁志远) \& G. L. Wu (吴光柳).2003. Cultivation technique of Taxus wallichiana var. mairei in Taishun. Journal of Zhejiang Forestry Science \& Technology (浙江林业科技), 23: $3 \sim 41$. (in Chinese)

Wu, B. H. (吴榜华) \& J.Z. Qi (戚继忠). 1995. Study on phytogeography of Taxus cuspidata. Chinese Journal of Applied Environment Biology (应用与环境生物学报), 1: 219 225. (in Chinese with English abstract)

Wu, B.H. (吴榜华), Q. C. Zhang (张启昌) \& D.Z. Li (李德 志). 1996. Study on growth and management of Taxus cuspidata. Journal of Jilin Forestry University (吉林林学院学报), 12: 125 129. (in Chinese with English abstract)

Yan, J. Q. (阎家麒) \& H. Liu (刘虹). 1994. Taxol extraction and mensuration of Taxus cuspidata. Chinese Journal of Pharmaceuticals(中国医药工业杂志), 25: $433 \sim 436$. (in Chinese with English abstract)

Yuan, Y.J., J.C. Li, Z. Q. Ge \& J. C. Wu. 2002. Superoxide anion burst and taxol production induced by $\mathrm{Ce}<\sup >4+</$ sup $>$ in suspension cultures of Taxus cuspidata. Journal of Olecular Catalysis B: Enzymatic, 18: $251 \sim 260$.

Zhou, Y. L. (周以良), D.Z. Huang (黄达章) \& Y.L. Zhang (张玉良). 1985. Trees and shrubs in less xingan mountains. China Forestry Publishing House. 251. (in Chinese)

Zhou, Y. L. (周以良). 1986. Ligneous flora of heilongjiang. Harbin: Heilongjiang Science \& Technology Press. $76 \sim 78$. (in Chinese)

Zhou, Y. L. (周以良). 1992. Vegetation of Less Xingan Mountains in China. Beijing: Science Press. 364. (in Chinese) 